\title{
unindra
}

Universitas Indraprasta PGRI

Address: Jl. Nangka No. 58 C (TB. Simatupang), Kel. Tanjung Barat, Kec. Jagakarsa, Jakarta Selatan 12530, Indonesia. +62 (021)

7818718 - 78835283; url: www.unindra.ac.id; cultural.syndrome@unindra.ac.id

\section{Rethinking Bamboo: An Asian Eco-Interior Design \\ Language with Ecological Branding in East Asia}

Nurhaya Baniyamin,

Shamzani Affendy Mohd Din

Department of Applied Arts \& Design

Kulliyyah of Architecture and Environmental Design

International Islamic University Malaysia

Correspondence regarding this article should be addressed to:

Nurhaya Baniyamin, nurhaya@iium.edu.my,

\section{Article History}

Received : 01-02-2020

Revised : 06-02-2020

Accepted : 07-02-2020

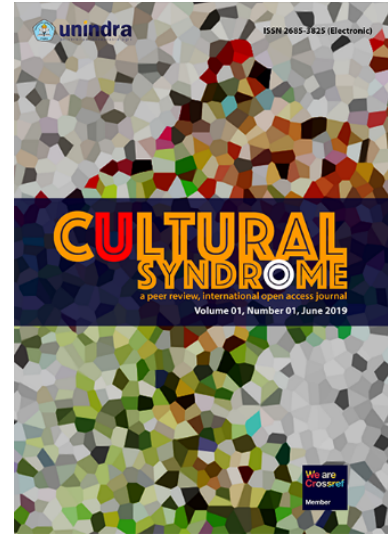

Cultural Syndrome

a peer review, internasional open access journal

e-ISSN: 2685-3825

Editor: iDAhmad Faiz Muntazori

Publication details, including author guidlines https://journal.unindra.ac.id/index.php/cusy/ about/submissions\#authorGuidelines

\section{How to cite this article (MLA 8th)}

Baniyamin, Nurhaya and Shamzani Affendy Mohd Din. "Rethinking Bamboo: An Asian Eco-Interior Design Language with Ecological Branding in East Asia." Cultural Syndrome, vol. 1, no. 2, 2019, pp. 79-95, doi:https://doi.org/10.30998/cs.v1i2.229.

The readers can link to article via https://doi.org/10.30998/cs.v1i2.229

\section{SCROLL DOWN TO READ THIS ARTICLE}

Universitas Indraprasta PGRI (as Publisher) makes every effort to ensure the accuracy of all the information (the "Content") contained in the publications. However, we make no representations or warranties whatsoever as to the accuracy, completeness, or suitability for any purpose of the Content. Any opinions and views expressed in this publication are the opinions and views of the authors, and are not the views of or endorsed by Universitas Indraprasta PGRI. The accuracy of the Content should not be relied upon and should be independently verified with primary sources of information.

\section{(c) $(\$)$}

This work is licensed under a Creative Commons Attribution-NonCommercial 4.0 International License.

Copyright by Nurhaya Baniyamin, Shamzani Affendy Mohd Din (2019)

The authors whose names are listed in this manuscript declared that they have NO affiliations with or involvement in any organization or entity with any financial interest (such as honoraria; educational grants; participation in speakers' bureaus; membership, employment, consultancies, stock ownership, or other equity interest; and expert testimony or patent-licensing arrangements), or non-financial interest (such as personal or professional relationships, affiliations, knowledge or beliefs) in the subject matter or materials discussed in this manuscript. This statement is signed by all the authors to indicate agreement that the all information in this article is true and correct 


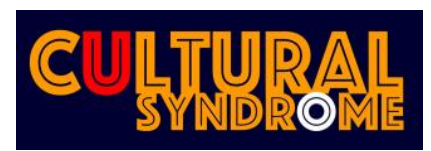

Vol.1, No.2, 2019, pp. 79-95

e-ISSN:2685-3825

https://doi.org/10.30998/cs.v1i2.229

\title{
Rethinking Bamboo:
}

\section{An Asian Eco-Interior Design \\ Language with Ecological Branding in}

\section{East Asia}

\author{
Nurhaya Baniyamin ${ }^{1}$, Shamzani Affendy Mohd Din ${ }^{2}$ \\ Department of Applied Arts \& Design \\ Kulliyyah of Architecture and Environmental Design \\ International Islamic University Malaysia
}

\begin{abstract}
This article takes a look and survey of the approaches in interior design possibilities and expressions in applying the use and particular structural qualities of bamboo. This particular material has gained much interest due to its quality of being rapidly replenishable, thus allowing it as an alternative to more depleting resources such as timber and other materials. The paper focuses on the higher applications of bamboo and the recent corporate space design and its typological function gain from the application of bamboo as an interior design strategy and aesthetics. With the move by the United Nation on having 17th initiatives under Sustainable Development Goals (SDGs), this study will discuss further how bamboo could be improving the quality of life in the countries with the tropical climate where bamboo vastly grown and reliable as one sustainable material in construction of structure outdoor, indoor and also to be used widely in arts \& craftsmanship in the region.
\end{abstract}

Keywords: bamboo, eco-interior, ecological branding

Correspondence author: Nurhaya Baniyamin, nurhaya@iium.edu.my, Kuala Lumpur, Malaysia

\section{Introduction}

Green materials, or materials with lower environmental impact are fast gaining recognition, acceptance and commercial viability in the building construction industry. There is a unique role of bamboo for environmental protection and sustainable lifestyles. The main purpose of the research is to feature the rich and distinctive role that bamboo 
can play in promoting ecological civilisation within the fields of architecture, construction, and interior design. Bamboo is gradually seen not only as sustainable crop; perceived as a kind of a fast-growing grass, but a rapidly renewable material in the industry. Having a growth cycle of 7 to 8 years, bamboo is currently on the rise not only as a raw material, but for its aesthetic possibilities.

\section{The rising economics of bamboo in Malaysia}

INBAR statistics show the global bamboo industry generates annual revenue of US $\$ 11$ billion which reached US $\$ 18$ billion in 2018. Malaysia's climate and fertile soil provides an excellent opportunity for the growth of tropical bamboos and the promotion of industrial plantations and value chain development. Among the current challenges facing Asia Nusantara's bamboo industry is crucial investments.

Sustainable design refers to interdependence between the built and natural environment; the efficient use of energy, land, and other natural, finite resources; the enhancement of communities; and the fostering of physical and emotional well-being. There is a steady increase in the knowledge and interest regarding bamboo as sustainable design in the industry. Promotion in sustainable design may increase local demand for new and further innovative products, thereby encouraging domestic and foreign investments. New investments are being sought and developed for the development of bamboo and its value chains and resources such as in plantations.

Bamboo is now considered as an important alternative material to timber. For example, in Malaysia, the government through the Malaysian Timber Industry Board (MTIB) is implementing activities according to the Bamboo Industry Development Action Plan for 2011-2020. In the Malay region, bamboos grow profusely in ex-logging areas throughout the country (Azmy "Three Malaysian Wild Bamboos"), on hill slopes, riverbanks and flat land. The vegetation can be pure or mixed with other tree species in the forest ( $\mathrm{Ng}$ and Shamsuddin).

Buluh semantan is one of the most important commercial bamboo species in Malaysia (Azmy "The Structure and Demography of Gigantochloa Scortechinii Natural Stand"). This species is being extracted from ex-logging areas in a haphazard way without systematic management. No proper conservation practices have been done on the natural stand bamboos in Malaysia. The bamboo culms are extracted from the forest from time to time without any management guidelines.

In order to ensure adequate supplies of bamboo resources in the future and to maintain a well-balanced forest environment, systematic management principles should be made available. With the application of systematic management principles on the natural stand bamboos, the production of bamboo stock can be increased (Liese; Mohammad; Numata).

Among the current challenges facing Malaysia's bamboo industry is crucial investments. Barriers for investments in the bamboo industry include a lack of product variety, lack of raw materials and lack of properly linked supply chains.

"The transformation of our current bamboo industry into a new era of higher value-added products will enable the industry to start contributing to the national 
economy,"said The Malaysian Timber Industry Board (MTIB) Director General Dr. Jalaluddin Harun. The transformation efforts now focus on the creation of more valueadded products, establishing the right supply chains and identifying the technical requirements for innovation. Bamboo products in construction and architectural works such as for flooring, flooring skirting, frames and doors, as well as dining set furniture could be developed as new local value-added products, he added, pointing out that bamboo's 'green material' status would be its biggest selling point (nst.com).

\section{Methods}

\section{Sustainability in design}

William McDonough states in his book Cradle to Cradle, "Most leading designers eschewed environment concerns. Many environmentally minded designers applied environmental solutions in isolation, tacking new technology onto the same old model. Even as architects and industrial designers began to embrace recycled or sustainable materials, they still dealt primarily with surfaces, with what looked good, what was easy to get, and what they could afford" (McDonough and Braungart).

The broad principles of sustainable design are fairly simple, "choose energy efficiency wherever possible; work in harmony with the natural features and resources surrounding the project site; and use materials that are sustainably grown or recycled rather than new materials from non-renewable resources". Sustainable design in construction better known as Green design is a design that conforms to environmentally safe and sound principles for building, as well as energy and material use. It is a partial solution to the global environmental crisis, diminishing natural resources, swift growth of economic activity and human population, damage to ecosystems, and loss of biodiversity.

\section{Bamboo - the ecological content}

Building and construction industries need to encourage the use of rapidly renewable natural materials and non-wood-based products in order to reduce environmental impact. According to Ghavami, one of the main shortcomings of bamboo, when used as a reinforcement and/or permanent shutter form with concrete, is the effect of water absorption. The capacity to absorb water was studied on several bamboo species. Therefore, the industries and the academic institutions should be working close to develop methods on reducing and minimising the weakness of bamboo and maintaining its strength and functionality more lasting in the future through research \& development (Ghavami).

Bamboo has a long and well-established tradition as a building material throughout the world's tropical and sub-tropical regions. It is widely used for many forms of construction, in particular for housing in rural areas. Bamboo is a renewable and versatile resource, characterized by high strength and low weight, and is easily worked using simple tools. As such, bamboo constructions are easy to build, resilient to 
wind and even earthquake forces (given the correct detailing) and readily repairable in the event of damage. Associated products (bamboo-based panels and bamboo reinforced concrete, for example) also find applications in the construction process (Jayanetti and Follett). Knowing the advantages of bamboos, the promotion in sustainable design in building construction may increase local demand for new and innovative products, thereby encouraging domestic and foreign investments by the government or private sectors. Besides its potential, there are also few identified weaknesses that need to be considered or minimised that is keeping the bamboo from dry, keeping the bamboo out of ground contact, ensuring good air circulation, and ensuring good visibility.

Bamboo need to be seen bigger prospects of construction materials in constructing bridges and also used widely as scaffolding materials (Jayanetti and Follett). The use of bamboo reinforced concrete can be a good reason to be considered because it is low cost compared with steel, readily available and its strength to weight ratio compares favorably with steel. Other applications of bamboo as the base panels. Most importantly, the key fundamental of the structural integrity of a framed construction is effective jointing for lasting strength and more works need to be made on bamboo is the developments in jointing technology while making it more economical bamboo structures.

The diversity of bamboo is itself reflected by its number of species, there are roughly 1000 species of bamboo found word wide. Bamboo grows very fast rather it is better to say extremely fast-growing grass. Bamboo can be considered an ecologically viable substitute for commonly used wood in many ways. Bamboo attains maturity in 3 years as compared to wood which takes almost more than 20 years (Khalil et al.). With all identified advantages of bamboo, new investments by the government or private agencies can be used for the development of necessary value chains and bamboo plantations. Not only the farmers will be benefited from growing and harvesting bamboo, but they will also able to polish their basic skills in terms of cultivation, being able to handle loss in marketing, and will also enhance further their empowering ability for handling more global market. According to Abdul Khalil et al., although the export trade of raw bamboo materials showed a decrease from US \$ 61 million in 2001 to US \$ 45 million in 2009, the decrease in export of bamboo may be due to the domestic utilization of bamboo (Khalil et al.). China has led as the biggest exporter to the USA and EU. With the current world demand for bamboo, this will definitely will give more positive impacts on society, economy, and nation. One of the ways in supporting this idea is to have a complete cycle value of chains from plantation, production, manufacturing, marketing, recycling, and reuse of bamboo at various levels. The idea has also been supported earlier by Van der Lugt et al. where they suggested to use life cycle costing (LCC) in order to make a complete cost comparison taking into consideration all costs occurring during the whole life span of a product. The initiative and awareness of bamboo can be started at the primary, secondary, and up to the higher education level. 


\section{Bamboo - the applications}

Bamboo products in construction and architectural works such as flooring, flooring skirting, frames, and doors, as well as dining set furniture, could be developed as new local value-added products, he added, pointing out that bamboo's 'green material' status would be its biggest selling point. Bamboo is seen and considered as a sustainable material locally and globally as it forms part of what is known as 'rapidly renewable materials', basically raw materials that can be regrown at a fast rate. William McDonough and M. Braungart stated "Imagine what you would come upon today at a typical landfill: old furniture, upholstery, carpets, televisions and plastic packaging. Resources are extracted, shaped into products, sold, and eventually disposed of in a 'grave' of some kind, usually a landfill or incinerator (McDonough and Braungart). Cradle-to-grave designs dominate modern manufacturing. For example, LEED Commercial Interiors list bamboo as an alternative under rapidly renewable materials.

Functionally Graded Composite-Bamboos are giant grass-like plants and not trees as commonly believed, belonging to the family of the Bambusoideae. The bamboo culm, in general, is a cylindrical shell, divided by transversal diaphragms at the nodes, and also, is an orthotropic material with high strength along and low strength transversal to its fibres (Ghavami). Physically, bamboo comes in a variety of sizes (length and thickness), it can be tightly packed together to create an opaque wall divider or can be stacked a few inches apart to allow the light to pass through. It is lightweight but incredibly durable. They are 2 types that are treated and non-treated. Basically, the treated bamboo normally will be kept inside the river for up to 1 year or it can also be kept in a water tank-mixed with chemicals for curing purposes. Treated bamboo will be in dark or blackened colour and can be used longer for usage outdoor, and can be used for higher strength structure. While the non-treated bamboo is the one in its dry yellow colour and been used widely for indoor structure and the making of arts \& craft by the artisans.

\section{Bamboo as basic Interior design elements}

On the most basic level, bamboo can be made into wall dividers. It comes in a variety of shapes and designs with interconnecting options that can accommodate even curved and angled walls. Bamboo is an all-natural, sustainable grass that looks rustic, but can easily be paneled with solid wood for a classy appearance. It can be painted or stained to match contemporary décor. A freestanding bamboo wall dividers are a portable option that can be moved to any part of the house or commercial space. Wallmounted ones are a more permanent option that attaches to the wall using brackets. It can either be a folding or a stationery design and is usually used in rooms that frequently need partitioning.

From an aesthetic viewpoint, even in the most basic elements in interiors, a vertically stacked mesh of thin bamboo screen can be horizontally arranged, while thicker bamboo stalks permanently attached to solid wooden frames, bamboo can also be inserted in the solid wooden frames and it can be stained to match the finish of the wood. It can be inserted in metal frames for the patio or the balcony. Natural exotic 
bamboo wood made it possible to create such a delicate, though spacious, design of a bamboo wall divider.

\section{Result and Discussion}

Case studies: Impact and Ideations of Bamboo in Interior Design in cities across Asia As the ecological trends continue, designers in Asia are making strides to create new ideas and pathways to promote a range of its locally available material. Bamboo is playing an increasingly crucial role in continuing to seek, develop and explore options and expressions that can somehow create a specific and unique aesthetic and expressions for bamboo in interior designs. While the use of bamboo in the hospitality and tourism industry and its buildings are well known, less is known on bamboo for more polished, and corporate branding and image, the following cases have been compiled which represents the cases from which designers have explored bamboo not only for its sustainable qualities but also its aesthetic contributions.

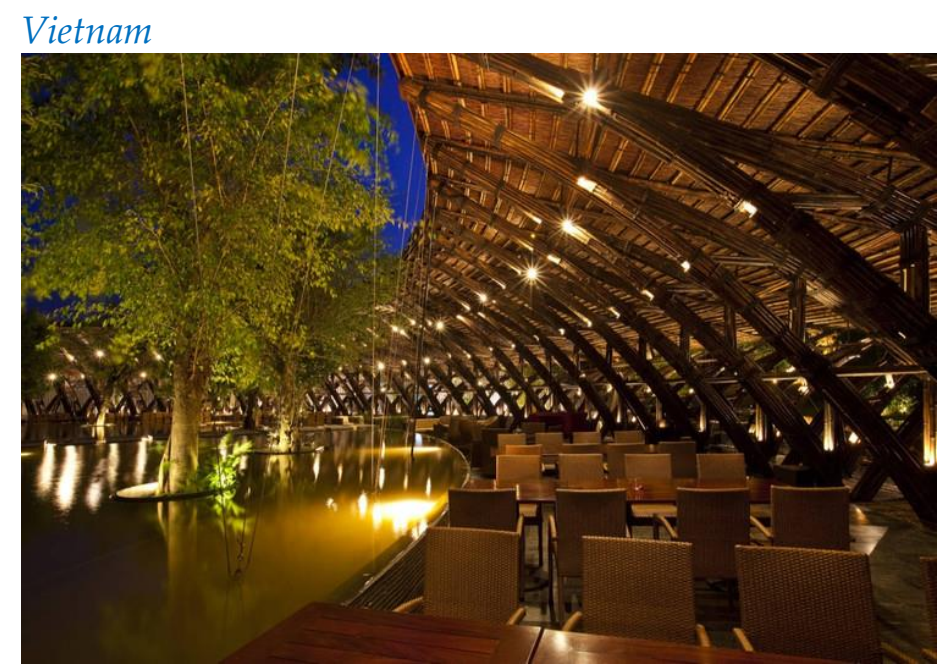

Fig. 1 The Bamboo Wing restaurant in HANOI, designed by VTN Architects (VTN Architecs, Source Image: Hiroyuki Oki)

The Bamboo Wing restaurant, built in 2010, has an area of $1600 \mathrm{~m} 2$ arises and evokes the form of bird wings that floats over the natural landscape of the site situated near Hanoi, Vietnam. VTN Architects, namely Vo Trong Nghia and Takashi Niwa. VTN Architects was already known for their works using bamboo in Vietnam, which due to the rise of sustainability standards has seen a resurgence in popularity as a building and design material. Vo Trong Nghia has a personal philosophy which aims to prove that sustainability is seen as stylish. Since establishing his firm in 2006, the Vietnamese architect has completed several bamboo projects, including restaurants, cafés, a community hall and Vietnam's national pavilion at the 2015 Milan Expo. 
The design process begins by studying the material properties of bamboo and the potential spaces and compositions in interior that it can create. The outcome is a composition and building which is a pure bamboo structure, using no steel or other manmade structural materials. Throughout the process, the idea of the bamboo structural and spatial qualities as a dynamic form of flying over the sky as bird wings was of high interest. It finally came into a finalised composition and space in which one can experience a 12-meter open space without any vertical columns.

Another example of VTN Architects's bamboo design - the curving Roc Von restaurant is formed of 12 huge bamboo columns that spread upwards, creating a canopy that covers a 6,560 square meter semi-outdoor dining area. This building, located on a 1,100 square meter area was completed in April 2015 and is deemed and recognised as a space where local and global visitors can feel a strong connection to the local culture of North Vietnam. The open quality of the space and usage of natural materials including bamboo had helped create this connection.

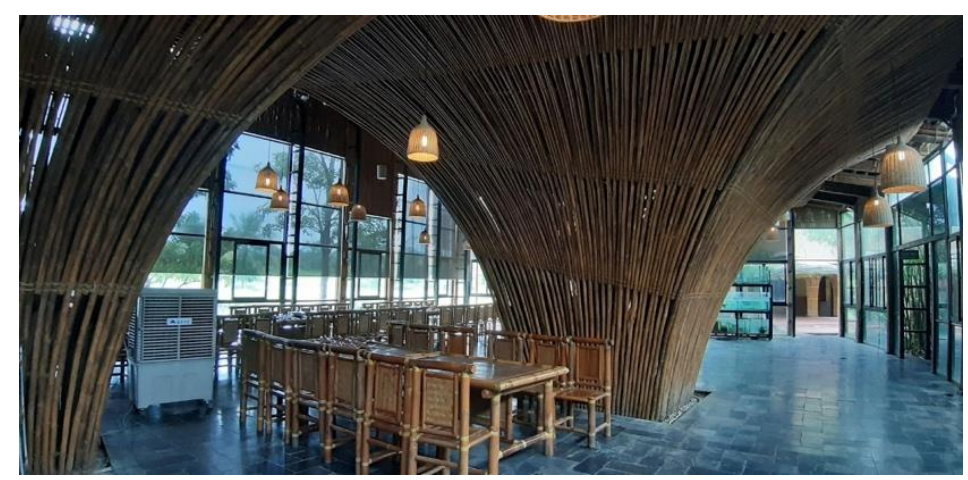

Fig. 2 Roc Von Restaurant in Hanoi

Image Source: Author

In general, the usage of bamboo in the interior design industry in Vietnam, Indonesia and Malaysia is in an upward trend. In Vietnam, particularly it is considered a significant part of the life of the Vietnamese culture and communities. As it is a traditional and artisanal traditions of Vietnam, the use of bamboo symbolises the unity of the Vietnamese spirit in interior design projects. The dichotomy of its character, the contrast of it being bendable, soft-edged yet durable and of high strength represents immortality for the Vietnamese culture and its people. This is because bamboo trees often grow in clusters with strong spirit and energy but also signifies the solidarity, diligence, and loyalty of their people, their homeland.

\section{Japan}

The renowned Japanese architect Kengo Kuma, leads Kengo Kuma \& Associates in Tokyo and Paris. The practice is presently well-known for its emerging language of design and architecture which references the architectonics of timber and bamboo. The underlying philosophy of the team draws its ideas from its attempts to counter a globalist and materialistic predisposition and attitude through more natural 
materials but composed in an innovative composition using local resources, fabric, texture, and alternative materials. The design principle strongly refers to the continuous idea and movement of 'contextualism' which is on the rise and emerge as a strong trend in East Asia. One of the latest projects of Kengo Kuma is the 'Pigment' shop completed at the end of 2015.

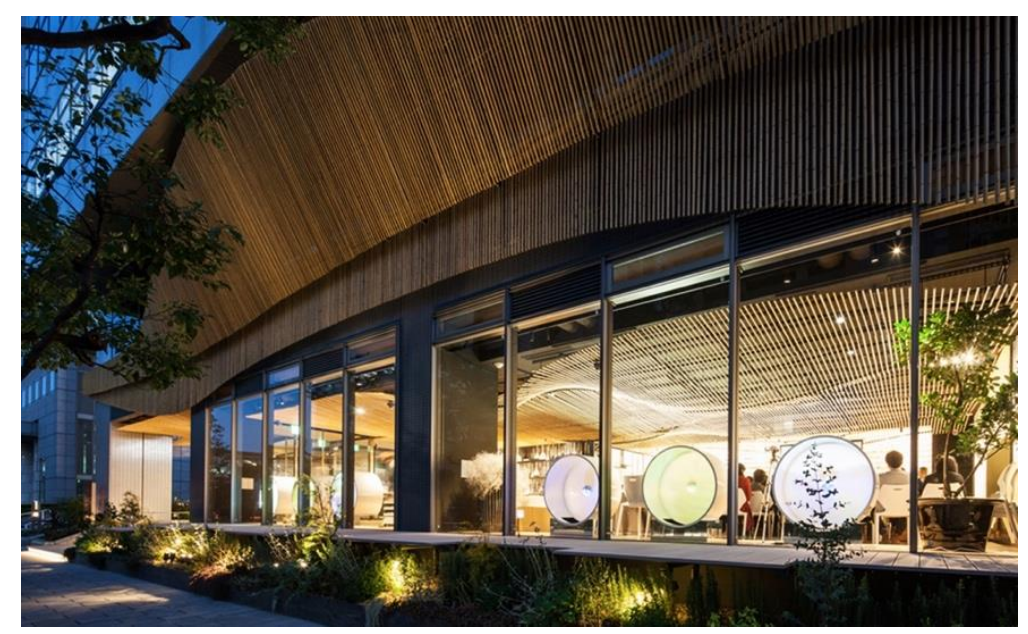

Fig. 3 View from the facade of Pigment shop (Image source: World Architecture Content Content)

The 'Pigment' shop and gallery is made up of a very thin bamboo material that gave the wavy shape of interior. The design created a smooth surface that is detailed with the traditional products inside. The whole surface of the interior covered by wood material. One of the aims of this project was to form a 3D curved surface in a frame of concrete, generated from computer technology. Laser-cut steel panels and thin bamboo are the basic materials to be used inside. A wave of bamboo for the shop is created, a purpose-built space to show and sell traditional pigment for Japanese painting, along with brushes and old inkstone.

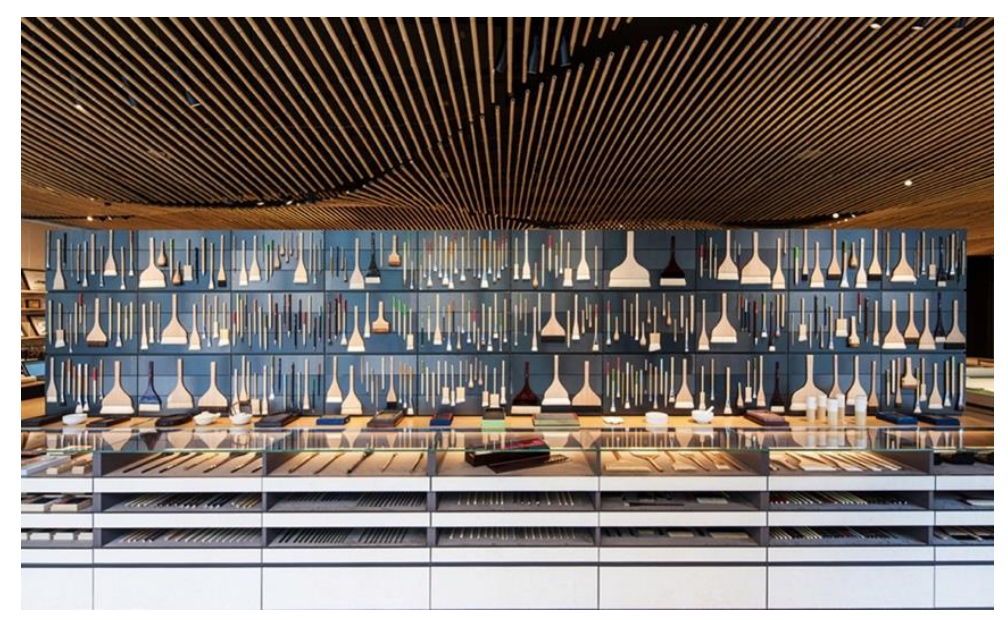

Fig. 4 Interior view with the traditional Japanese products (Image source: World Architecture Content Content) 
China

The first International Bamboo Architecture biennale was in 2016. Curated by 12 international architects, the biennale reveals how the traditional material can be incorporated into contemporary design. The plant serves as the base to new buildings in the small village of Baoxi - including a youth hostel and a ceramics museum, which the permanent structures hopes to draw tourism through supplementary infrastructures such as a visitor building, hotel, and learning centre. All the image source credited to Stewart - "First Bamboo Biennale Creates Cutting-Edge Structures in Small Chinese Village." in https://Mymodernmet.Com.

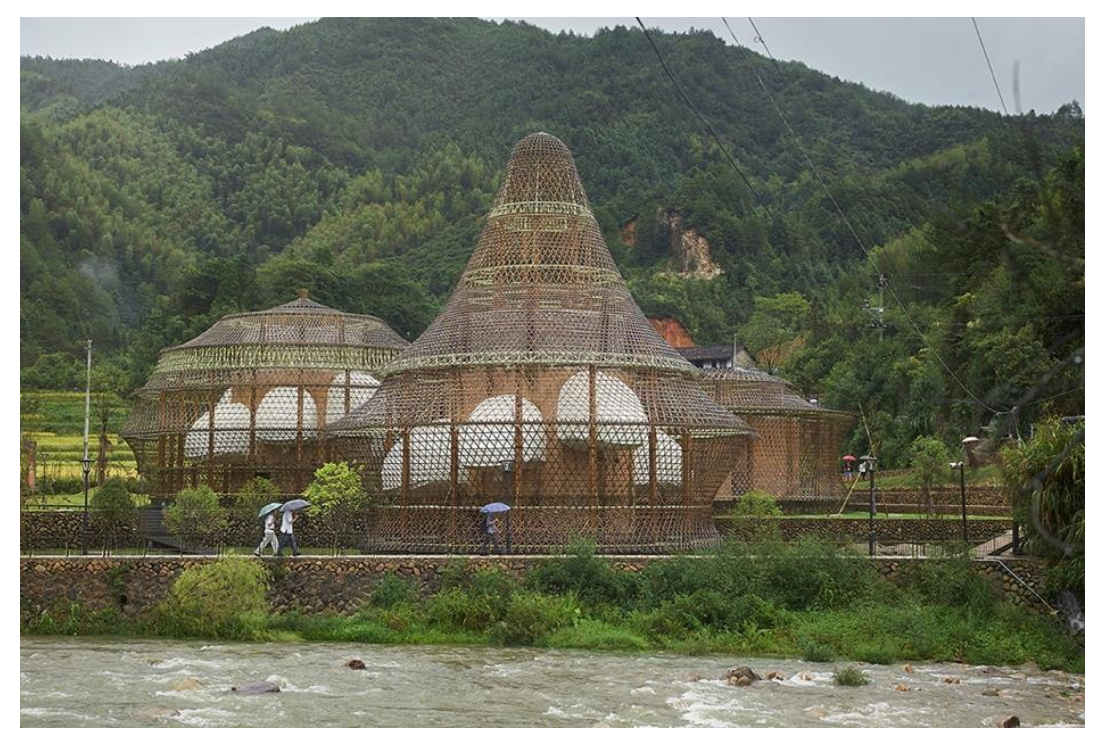

Fig. 5 Youth Hostel / Design Hotel by Anna Heringer

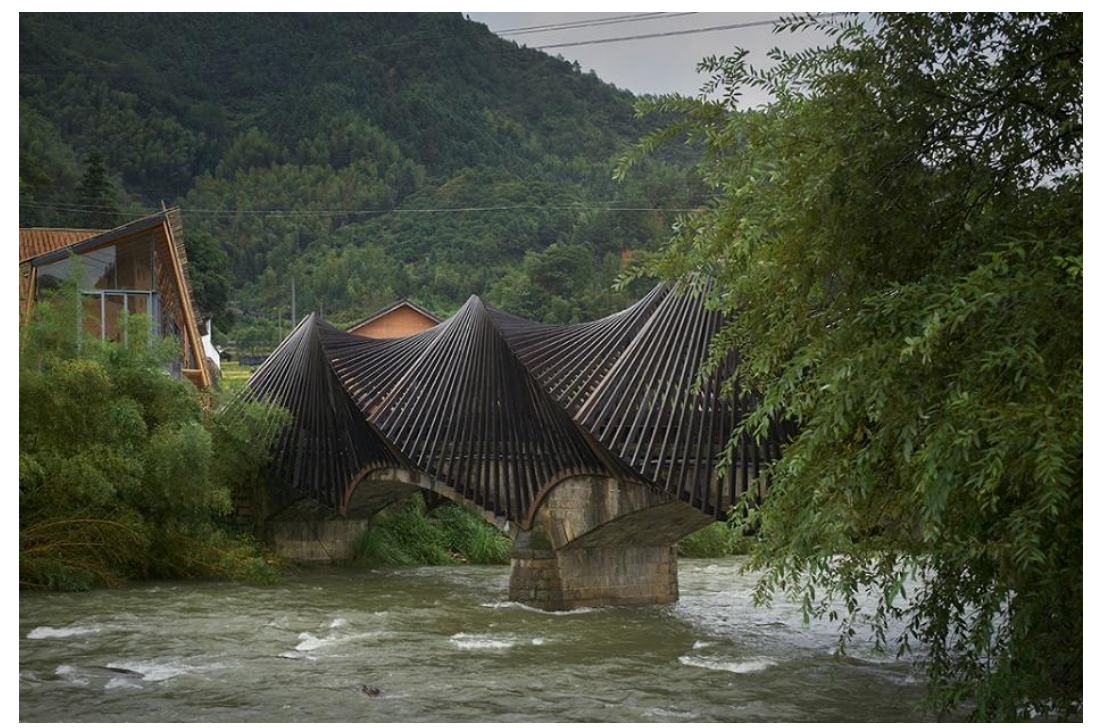

Fig. 6 Bridge by Ge Quantao 


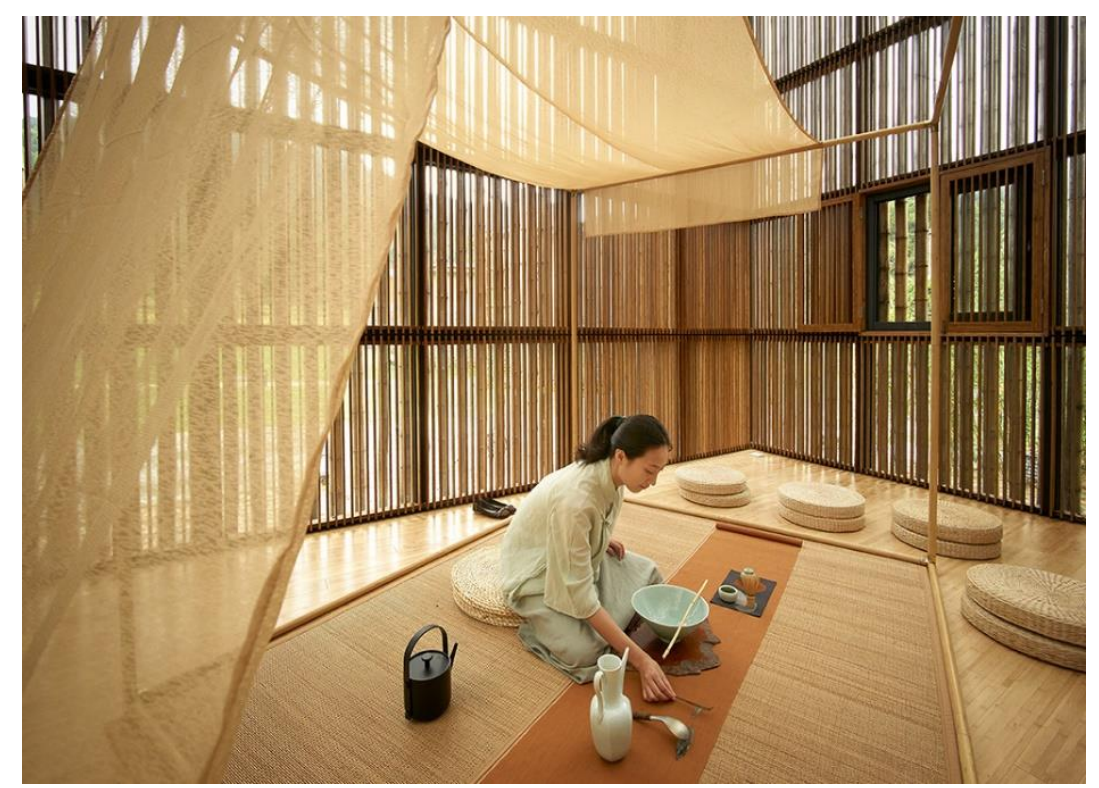

Fig. 6 Bamboo product research and design center (interior) by Li Xiaodong

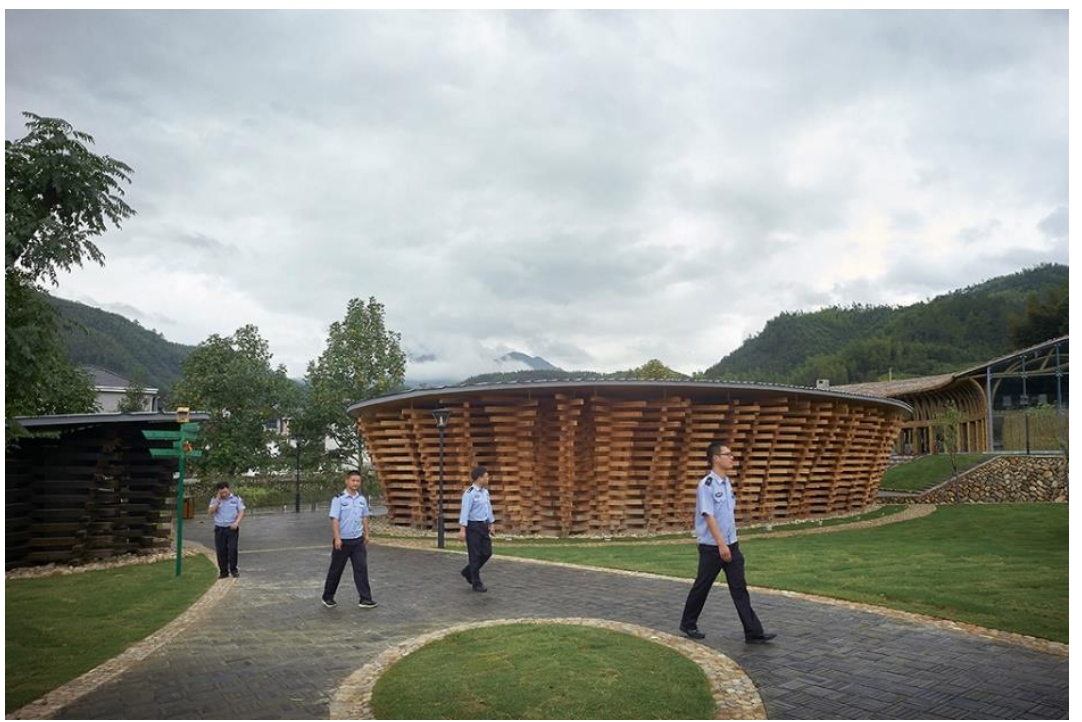

Fig. 7 Contemporary celadon ceramic museum by Kengo Kuma 


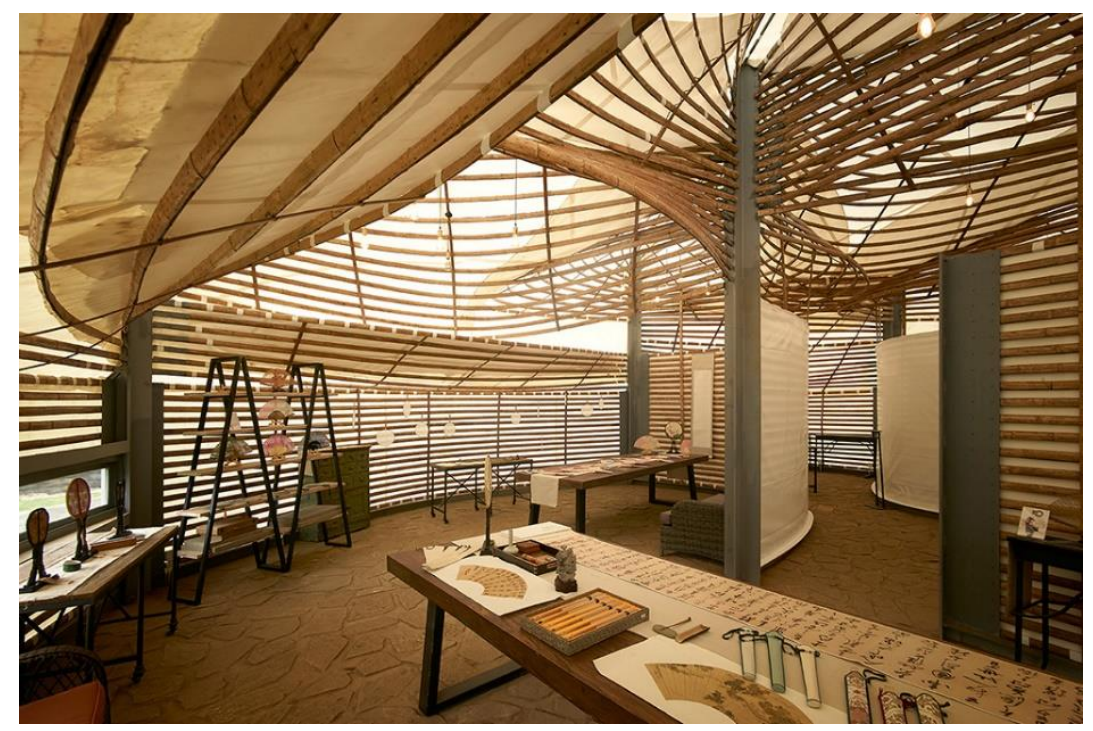

Fig. 8 Interior view of celadon ceramic museum

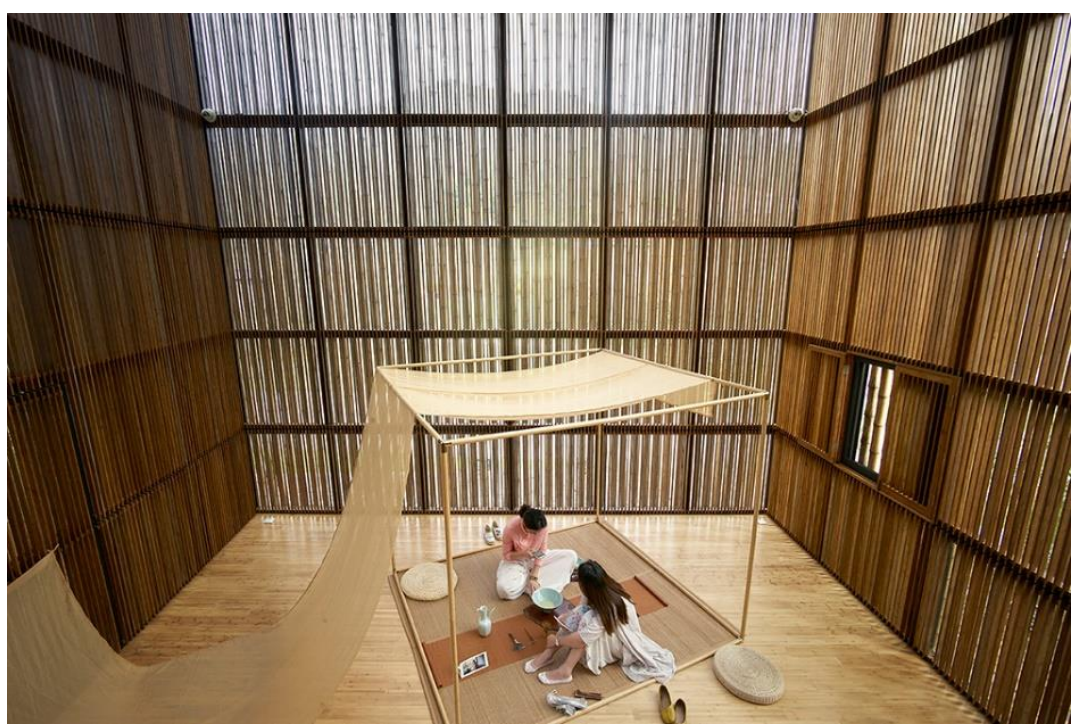

Fig. 9 Bamboo product research and design center (interior) by Li Xiaodong 


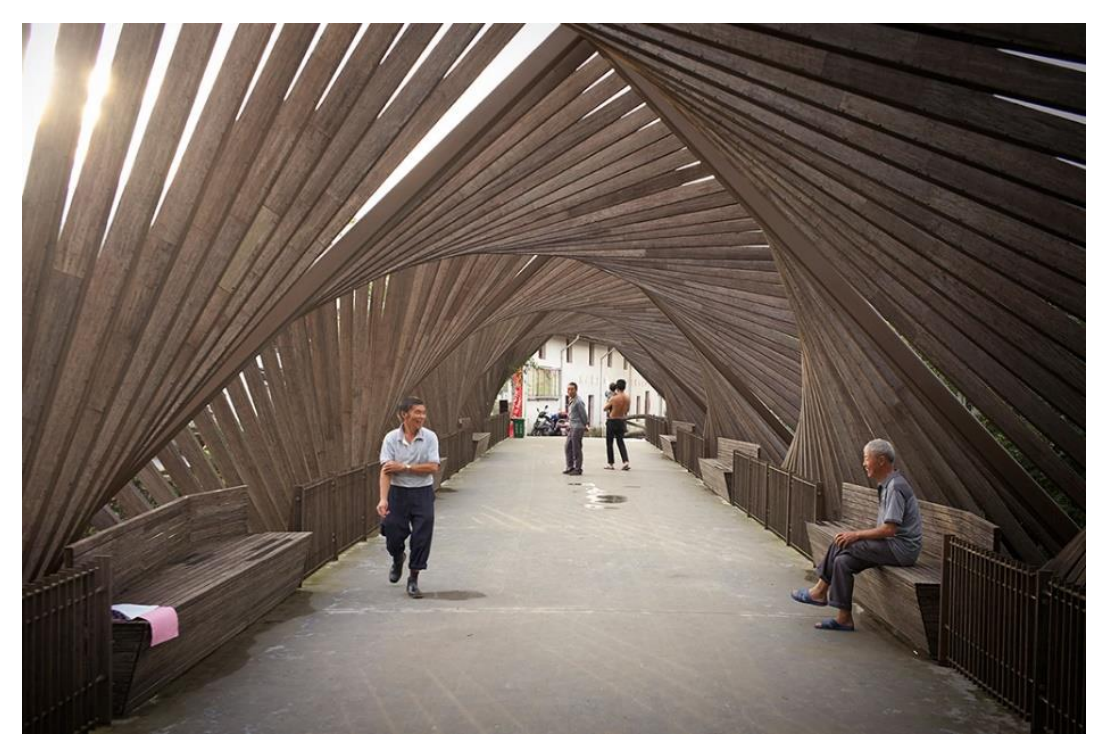

Fig. 10 Bridge by Ge Quantao

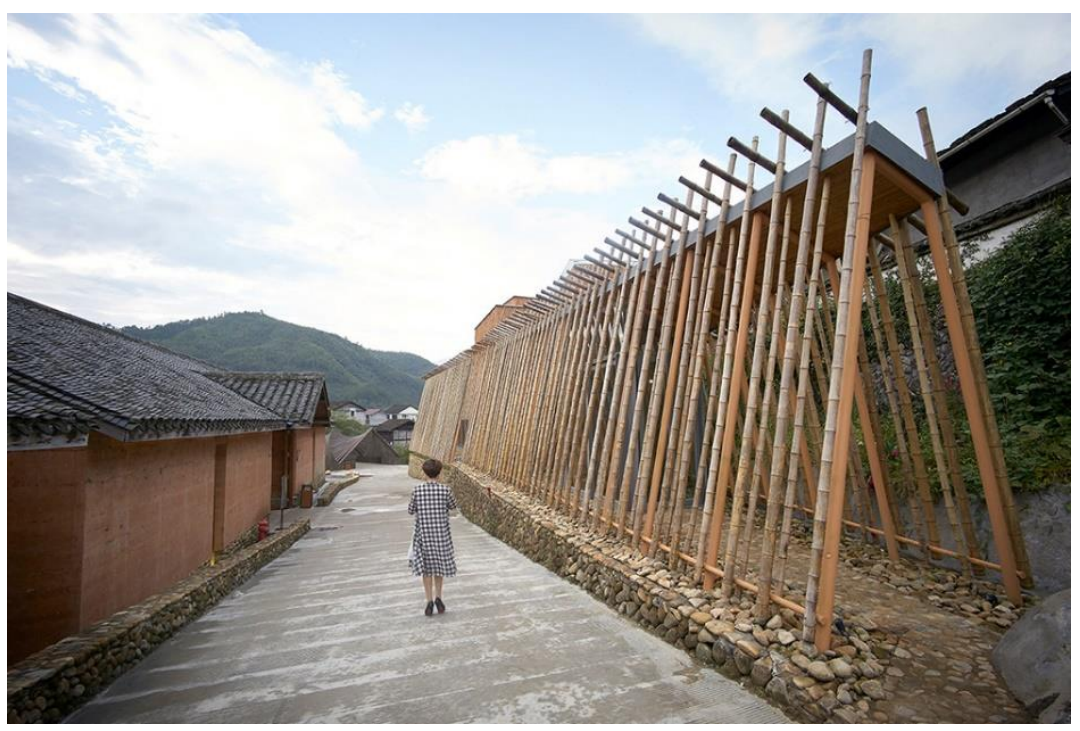

Fig. 11 Invited ceramist workshop by Keisuke Maeda 


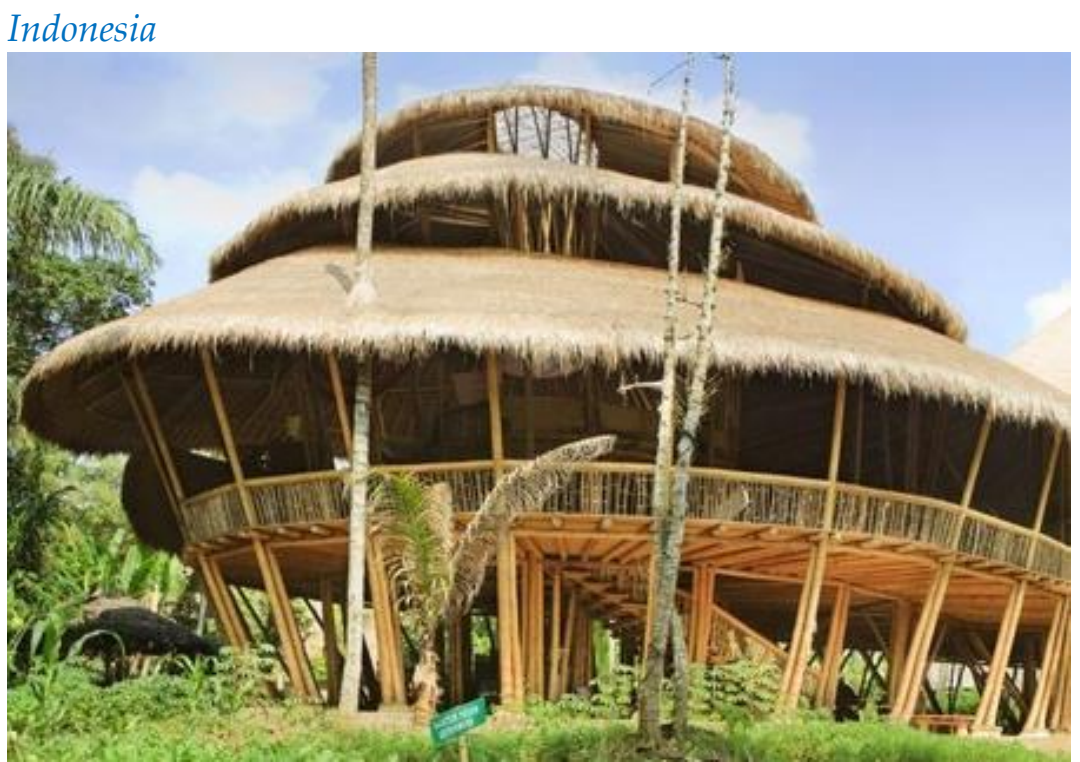

Fig. 12 The Green Village built in 2010 by Elora Hardy

(Ibuku Architects, Source Image: Jimbawan, Agung Dwi, Rio Helmi)

According to the architect Elora Hardy, the Green Village was designed and constructed based on the architectural concepts of sustainable principles and artisan craftsmanship. Green School, PT Bamboo Pure, and Green Village are the main anchors of the green development area. The concept is to create beautiful living spaces, in which people can live where luxury and comfort fit into natural landscapes. Interconnected with each other on a green zone which sustain themselves.

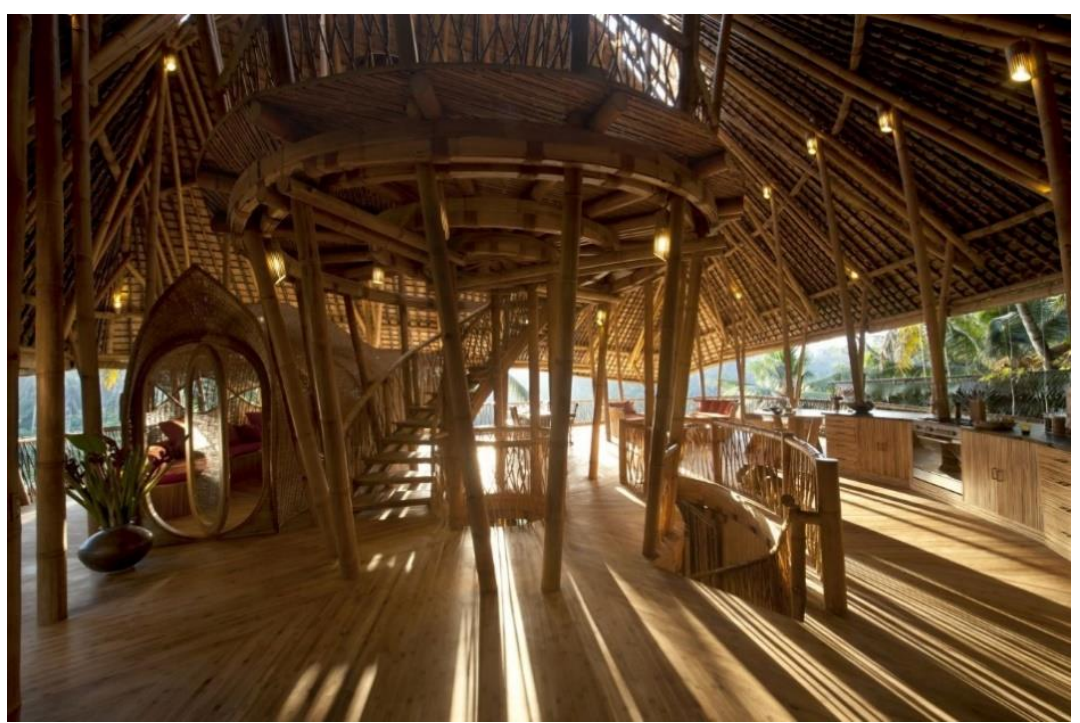

Fig. 13 The Bamboo houses are designed with rare views of the sacred Ayung River and the volcanoes of Bali (Ibuku Architects, Source Image: Jimbawan, Agung Dwi, Rio Helmi) 


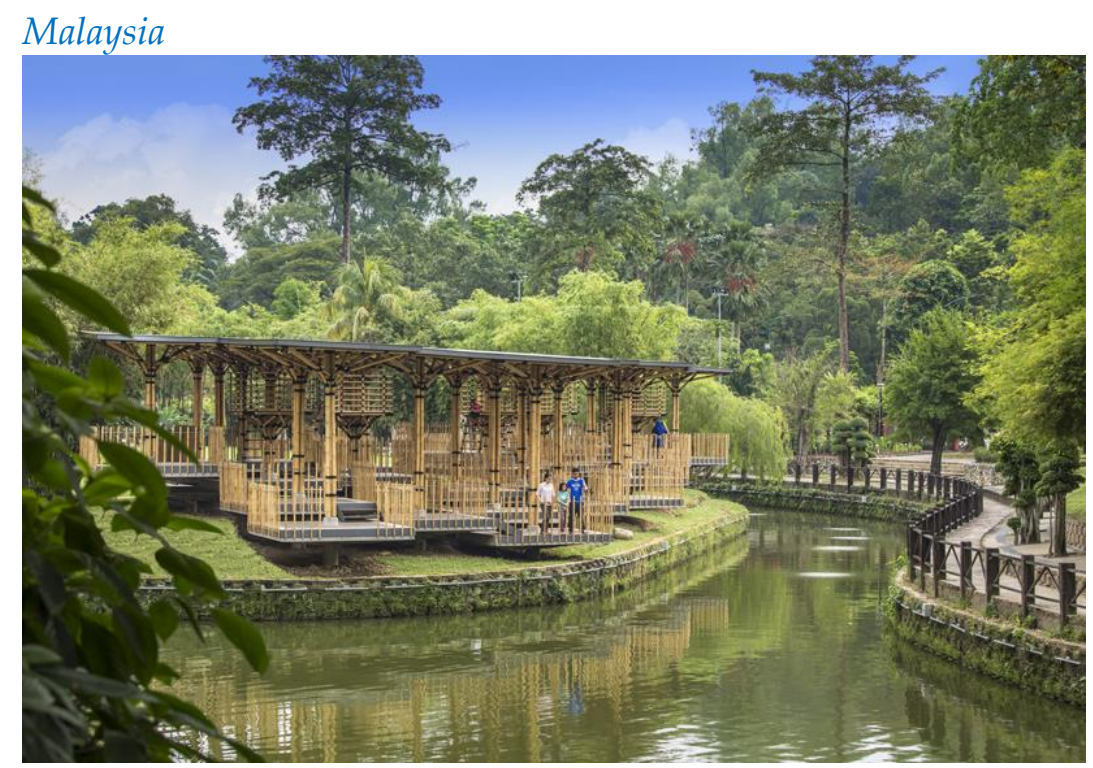

Fig. 13 Bamboo Playhouse

(Eleena Jamil Architect)

Bamboo flourishes in Malaysia where it has almost 50 species growing, of which 25 is indigenous. There are several species that have thick culm walls with strengths suitable to use in construction. The Bamboo Playhouse is a public pavilion located at Perdana Botanical Gardens, Kuala Lumpur. The pavilion is located on a small island in the lake and is used by many as a place to meet, rest and play. The project demonstrate that bamboo is a sustainable building material, and it became first formal bamboo structure in the country when it was completed in 2015 (Architect).

Located along the edge of the lake, the playhouse is an open structure with raised square platforms set at multiple levels. Idea for the playhouse stems from traditional vernacular structures called the 'wakaf' which are originally found in villages or 'kampungs'. It offers a series of indefinite spaces, with many opportunities of use and occupation.

\section{Impact on Society, Economy and Nation}

Local criteria and standards of sustainability

The Green Building Index (GBI) and MyCREST (Malaysia Carbon Reduction sustainability tool) for example, recognizes bamboo as one of the green material which can replace timber and other more rapidly depleting resources. Bamboo can be developed specifically for the Malaysian tropical weather, environmental and developmental context, cultural and social needs. The GBI initiative, for example, aims to assist the building industry in its march towards sustainable development. Thus with the growth in green buildings, the Green Building Index Interior Tool is jointly developed by MGBC (Malaysia Green Building Confederation) and MIID (Malaysian Institute of Interior Designers) and the GBI Technical Committee for Green Building 
Index have forwarded a range for green alternatives in terms of materials and fit-outs (Green Buiding Index).

Among the current challenges facing Malaysia's bamboo industry is crucial investments. Barriers to investments in the bamboo industry include a lack of product variety, lack of raw materials and lack of properly linked supply chains. The transformation of the current bamboo industry into a new era of higher value-added products will enable the industry to start contributing to the national economy.

\section{Conclusion}

Bamboo can be seen as a great, reliable and sustainable materials for building construction in the country with the tropical climate. The ability of bamboo to be treated making it stronger in taking bigger load structure with the right techniques and construction. Bamboo also has been recognised as sustainable as it does not produce any $\mathrm{CO} 2$ to the atmosphere and it supports few Sustainable Goals Development (SGD)s namely i. No.11- Sustainable Cities and Communities, and No.13-Climate Action. It is hope the government will continue to support through various initiatives and promotion of bamboo as sustainable materials for building construction materials, and also in innovation of arts \& craftsmanship.

\section{References}

Architect, Eleena Jamil. "Bamboo Playhouse." Eleena Jamil Architect https://ejarchitect.com/portfolio/bamboo-playhouse/.

Azmy, HM. "The Structure and Demography of Gigantochloa Scortechinii Natural Stand." Japan Bamboo Journal, vol. 9, no. 19, 1991, pp. 21-26.

Azmy, HM. "Three Malaysian Wild Bamboos." Nature Malaysiana, vol. 16, no. 4, 1991, pp. 130-135.

Ghavami, Khosrow. "Bamboo: Low Cost and Energy Saving Construction Materials." Modern bamboo structures, edited by Masafumi Inoue Yan Xiao, Shyam K. Paudel, CRC Press, 2008, pp. 17-34. https://www.taylorfrancis.com/books/e/9780429207341/chapters/10.1201/978020 3888926-6.

Green Buiding Index. "Gbi Design Reference Guide - Interiors (Id) V1.01." edited by GREENBUILDINGINDEX SDN 2019. https://new.greenbuildingindex.org/Files/Resources/GBI\%20Tools/GBI\%20Desi gn\%20Reference\%20Guide\%20-\%20Interiors\%20V1.01.pdf. 
Ibuku Architects. "The Green Village." arcdaily https://www.archdaily.com/296667/thegreen-village-pt-bambu?ad medium=gallery.

Jayanetti, DL and PR Follett. "Bamboo in Construction." Modern Bamboo Structures, edited by Masafumi Inoue Yan Xiao, Shyam K. Paudel, CRC Press, 2008, pp. 35-44. https://www.taylorfrancis.com/books/e/9780429207341/chapters/10.1201/978020 $\underline{3888926-7}$.

Khalil, HPS Abdul et al. "Bamboo Fibre Reinforced Biocomposites: A Review." Materials $\mathcal{E}$ Design, vol. 42, 2012, pp. 353-368, doi:https://doi.org/10.1016/j.matdes.2012.06.015.

Liese, Walter. "Bamboos-Biology, Silvics, Properties, Utilization." TZ Verlagsgesellschaft http://agris.fao.org/agris-search/search.do?recordID=DE87T0876. Accessed December 102019.

McDonough, William and Michael Braungart. Remaking the Way We Make Things: Cradle to Cradle. vol. 1224942886, North Point Press, 2002.

Mohammad, M Fateh. "The Bamboo Forests of Hoshiarpur District Punjab." Indian Forester, vol. 57, no. 10, 1931, pp. 491-512, http://www.indianforester.co.in/index.php/indianforester/article/view/20026.

Ng, F.S.P. and M.N. Shamsuddin. "Country Reports: Malaysia." Bamboo research in Asia: , edited by Gilles Lessard and Amy Chouinard, vol. 229, The International Development Research Centre and International Union of Forestry Research Organizations, 1980.

nst.com. "Bamboo Trade Deficit to Be Eliminated in 5 Years: Mtib." New Straits Time, May $192015 . \quad$ https://www.nst.com.my/news/2015/09/bamboo-trade-deficit-beeliminated-5-years-mtib.

Numata, M. "Structure and Succession of Bamboo Vegetation." Ecology of Grasslands and Bamboolands in the World, edited by Makoto Numata and Dr. W. Junk, 1979.

Oki, hiroyuki. "Bamboo Wing / Vtn Architects." Archdaily https://www.archdaily.com/219880/bamboo-wing-vo-trongnghia?ad medium=gallery.

Stewart, Jessica. "First Bamboo Biennale Creates Cutting-Edge Structures in Small Chinese Village." https://mymodernmet.com/bamboo-architecture-biennale/.

Van der Lugt, P et al. "An Environmental, Economic and Practical Assessment of Bamboo as a Building Material for Supporting Structures." Construction and 
Nurhaya Baniyamin, Shamzani Affendy Mohd Din (@ 2019)

building materials, vol. 20, no. 9, 2006, pp. 648-656, https://doi.org/10.1016/j.conbuildmat.2005.02.023.

World Architecture Content. "Kengo Kuma Designed a Wave of Bamboo for the Interior of 'Pigment' Shop in Tokyo." Worldarchitecture https://worldarchitecture.org/architecture-news/ceggh/kengo-kuma-designeda-wave-of-bamboo-for-the-interior-of-pigment-shop-in-tokyo.html. 